Pacific Journal of Mathematics

MAXIMAL SUBFIELD OF TENSOR PRODUCTS 


\title{
MAXIMAL SUBFIELDS OF TENSOR PRODUCTS
}

\author{
Burton Fein and Murray Schacher
}

Let $D_{1}$ and $D_{2}$ be finite-dimensional division rings with center $K$ such that $D_{1} \otimes_{K} D_{2}$ is a division ring. If $L_{1}$ and $L_{2}$ are maximal subfields of $D_{1}$ and $D_{2}$, respectively, then clearly $L_{1} \otimes_{K} L_{2}$ is a maximal subfield of $D_{1} \otimes_{K} D_{2}$. In this note the converse question is considered: does there exist a maximal subfield $L$ of $D_{1} \otimes_{K} D_{2}$ which is not isomorphic to $L_{1} \otimes_{K} L_{2}$ for maximal subfields $L_{1}$ and $L_{2}$ of $D_{1}$ and $D_{2}$ ? Examples are given to show that such noncomposite $L$ may fail to exist even when $K$ is a local field. For $K$ an algebraic number field, however, it is shown that infinitely many noncomposite $L$ always exist.

We say that a division algebra with center a field $K$ is a $K$-division ring if it is finite-dimensional over $K$. Throughout this note $D_{1}$ and $D_{2}$ will denote $K$-division rings such that $D_{1} \otimes_{K} D_{2}$ is a $K$-division ring. We say that a maximal subfield $L$ of $D_{1} \otimes_{K} D_{2}$ is a composite if $L \cong L_{1} \bigotimes_{K} L_{2}$ where $L_{1}$ and $L_{2}$ are maximal subfields of $D_{1}$ and $D_{2}$, respectively.

A sufficient condition for $D_{1} \otimes_{K} D_{2}$ to be a division ring is for $\left(\left[D_{1}: K\right],\left[D_{2}: K\right]\right)=1 \quad[2$, Theorem 10, p. 52]. This condition is necessary if $K$ is either an algebraic number field or a local field since for these $K$ the exponent of a $K$-division ring equals its index [2, Theorem 25, p. 144, and Theorem 32, p. 149]. This condition is not, however, necessary for $K$ arbitrary, as is shown in [1]. We begin by determining, for the case when $\left(\left[D_{1}: K\right],\left[D_{2}: K\right]\right)=1$ necessary and sufficient conditions for a maximal subfield of $D_{1} \bigotimes_{K} D_{2}$ to be a composite.

Theorem 1. Let $D_{1}$ and $D_{2}$ be K-division rings such that $\left(\left[D_{1}: K\right],\left[D_{2}: K\right]\right)=1$, and let $L$ be a maximal subfield of $D_{1} \bigotimes_{K} D_{2}$. Then $L$ is a composite if and only if $L$ has subfields $L_{1}$ and $L_{2}$ with $\left[L_{1}: K\right]^{2}=\left[D_{1}: K\right]$ and $\left[L_{2}: K\right]^{2}=\left[D_{2}: K\right]$.

Proof. Let $n_{i}=\left[D_{i}: K\right]^{1 / 2}, i=1,2$. If $L_{i}$ is a maximal subfield of $D_{i}$ then $\left[L_{i}: K\right]=n_{i}, i=1,2$. It follows that if $L=L_{1} \otimes_{K} L_{2}$ is a composite with $L_{i}$ a maximal subfield of $D_{i}$, then $\left[L_{i}: K\right]=n_{i}$, $i=1,2$. This establishes one direction of the Theorem.

Suppose now that $L$ has subfields $L_{1}$ and $L_{2}$ with $\left[L_{i}: K\right]=n_{i}$, $i=1,2$. Since $L$ is a maximal subfield of $D_{1} \otimes_{K} D_{2}$ we have $[L: K]=n_{1} n_{2}$. As $\left(n_{1}, n_{2}\right)=1$, it follows that $L \cong L_{1} \otimes_{K} L_{2}$. Thus to conclude $L$ is a composite we need only show that $L_{i}$ splits $D_{i}$, 
$i=1,2$ [2, Theorem 27, p. 61]. We have $\left(D_{1} \bigotimes_{K} D_{2}\right) \bigotimes_{K} L \cong$ $\left[\left(D_{1} \bigotimes_{K} L_{1}\right) \bigotimes_{L_{1}} L\right] \bigotimes_{L}\left[\left(D_{2} \bigotimes_{K} L_{1}\right) \bigotimes_{L_{1}} L\right]$. Since $L$ splits $D_{1} \bigotimes_{K} D_{2}$, $\left(D_{1} \otimes_{K} L_{1}\right) \bigotimes_{L_{1}} L=A_{1}$ is in the class of the opposite algebra of $A_{2}=\left(D_{2} \otimes_{K} L_{1}\right) \otimes_{L_{1}} L$ in the Brauer group of $L$. In particular, these algebras have the same exponent. Since $\left(n_{1}, n_{2}\right)=1$ and the exponent of $A_{i}$ divides $n_{i}$, it follows that $A_{1}$ and $A_{2}$ are complete matrix algebras. Thus $L$ splits $D_{1} \otimes_{K} L_{1}$. Since $n_{1}$ is prime to $\left[L: L_{1}\right]=n_{2}, L_{1}$ splits $D_{1}$. Similarly, $L_{2}$ splits $D_{2}$, proving the proposition.

Corollary 2. Let $D_{1}$ and $D_{2}$ be $K$-division rings such that $\left(\left[D_{1}: K\right],\left[D_{2}: K\right]\right)=1$ and let $L$ be a maximal subfield of $D_{1} \otimes_{K} D_{2}$. If $L$ is Galois over $K$ with solvable Galois group, then $L$ is a composite. In particular, if $K$ is a local field and $L$ is Galois over $K$, then $L$ is a composite.

Proof. Take $G_{i}$ to be a Hall subgroup of order $\left[D_{i}: K\right]^{1 / 2}$ of the Galois group of $L$ over $K$. Let $L_{1}$ and $L_{2}$ be the fixed fields of $G_{2}$ and $G_{1}$, respectively. Then $L \cong L_{1} \otimes_{K} L_{2}$, and $L$ is composite by Theorem 1. The final assertion of the corollary follows from the result that Galois groups over local fields are solvable [6, Proposition 3.6.6, p. 101].

Corollary 2 is false without the restriction that $L$ have a solvable Galois group. By [5, Theorem 9.1, p. 472] there is a field $K$, a $K$-division ring $D$, and a maximal subfield $L$ of $D$ such that $L$ is a Galois extension of $K$ with group $A_{5}$. By [2, Theorem 18, p. 77], $D \cong D_{1} \otimes_{K} D_{2}$ where $D_{1}$ and $D_{2}$ are $K$-division rings with $D_{1}$ of index 20 and $D_{2}$ of index 3 . However, $L$ clearly has no subfield $L_{2}$ with $\left[L_{2}: K\right]=3$, since $A_{5}$ has no subgroup of order 20 .

Theorem 1 is false without the assumption that $\left(\left[D_{1}: K\right],\left[D_{2}: K\right]\right)=$ 1. In [1] an example is presented of two quaternion algebras $D_{1}$ and $D_{2}$ central over a field $K$ such that $D_{1} \otimes_{K} D_{2}$ is a cyclic division algebra. If $L$ is a maximal subfield of $D_{1} \otimes_{K} D_{2}$ with $L \mid K$ cyclic, then $L$ contains a subfield of degree two over $K$ but is not a composite as composites would have Galois group $Z_{2} \times Z_{2}$.

While one might expect that there should always exist maximal subfields of $D_{1} \otimes_{K} D_{2}$ which are not composites, this is not the case even when $K$ is a local field. Our next result treats the case when $K$ is local and $\left[D_{1} \otimes_{K} D_{2}: K\right]^{1 / 2}$ is a product of two primes. The general case may be expected to be much more complicated.

THEOREM 3. Let $p$ and $r$ be distinct primes, $p<r$, and let $K$ be a local field with residue class field $G F(q)$ where $p \nmid q, r \nmid q$. Let $D_{1}$ and $D_{2}$ be $K$-division rings of indices $p$ and $r$ respectively. If either $p \nmid r-1$ or $q \equiv 1(\bmod p r)$, then every maximal subfield of 
$D_{1} \otimes_{K} D_{2}$ is a composite. If $p \mid r-1$ there are infinitely many primes $q$ and $Q_{q}$-division rings $D_{1}$ and $D_{2}$ (where $Q_{q}$ is the $q$-adic field) of indices $p$ and $r$, respectively, having maximal subfields which are not composites.

Proof. Suppose $p \nmid r-1$ or $q \equiv 1(\bmod p r)$. Let $L$ be a maximal subfield of $D_{1} \otimes_{K} D_{2}$. Then $[L: K]=p r$. Since $p \nmid q, r \nmid q, L$ is tamely ramified over $K$. $L$ will have subfields of degrees $p$ and $r$ over $K$ if $L$ is either unramified or totally ramified over $K$. From Corollary 2 we also see that $L$ will be a composite if $L$ is Galois over $K$. Let $e$ and $f$ be, respectively, the ramification and residue class degrees of $L$ over $K$. Thus $e f=p r$ and we may assume that $e>1$ and $f>1$. If $q \equiv 1(\bmod e)$ then $L$ is normal over $K$ [3, Theorem 6 , p. 680]. Thus $L$ is a composite if $q \equiv 1(\bmod p r)$, so we assume that $p \nmid r-1$ and $e \nmid q-1$. By [3, Theorem 2, p. 678], we may assume that $L=K(\zeta, \alpha)$, where $\zeta$ is a primitive $\left(q^{f}-1\right)$ th root of unity, $\alpha^{e}=\zeta^{i} \pi, i$ is an integer, and $\pi$ is a prime element of $K$. Let $q^{f}-1=(q-1) t$. If $e$ divided $t$, then $q^{f} \equiv 1(\bmod e)$. But $(f, e-1)=1$ since $p \nmid r-1$ and $p<r$. Thus $q \equiv 1(\bmod e)$, against our assumption. Thus $(e, t)=1$ so there is an integer $j$ with $j t \equiv i$ $(\bmod e)$. Let $\beta$ be any root of $x^{e}-\zeta^{j t} \pi$ in an algebraic closure of $K$. Then $K(\zeta, \beta)$ is isomorphic to $L$ by [3, Theorem 3, p. 679]. But $\zeta^{t} \in K$ since $K$ contains all $(q-1)$ th roots of unity, so $[K(\beta): K]=e$. Thus $L$ has a subfield isomorphic to $K(\beta)$ which is of degree $e$ over $K$. Since $L$ also contains an unramified extension of degree $f$ over $K$, Theorem 1 shows $L$ is a composite.

Now suppose $p \mid r-1$. Let $b$ be an integer, $b \neq 1(\bmod r)$, $b^{p} \equiv 1(\bmod r)$. Take $q$ a prime, $q \equiv b(\bmod r)$. There are infinitely many such $q$ by Dirichlet's theorem. If $q^{p}-1=(q-1) t$, then $r$ divides $t$. Let $D_{1}$ and $D_{2}$ be $Q_{q}$-division rings of indices $p$ and $r$ respectively. Let $\zeta$ be a primitive $\left(q^{p}-1\right)$ th root of unity and let $\alpha^{r}=\zeta q$. Since $\left[Q_{q}(\zeta, \alpha): Q_{q}\right]=p r, Q_{q}(\zeta, \alpha)$ is a maximal subfield of $D_{1} \otimes_{K} D_{2}$ [2, Theorem 23, p. 144]. If $Q_{q}(\zeta, \alpha)$ were a composite, it would have a subfield $E$ with $\left[E: Q_{q}\right]=r . E$ would be totally and tamely ramified over $Q_{q}$, and so $E \cong Q_{q}(\beta)$ where $\beta^{r}=\zeta^{t j} q$ for some integer $j$. Thus $Q_{q}(\zeta, \alpha) \cong Q_{q}(\zeta, \beta)$ so $1 \equiv j t \quad(\bmod d)$ where $d=$ $\left(r, q^{p}-1\right)$ by [3, Theorem 3, p. 678]. Since $d=r$, we have $j t \equiv 1$ $(\bmod r)$. But $r \mid t$, a contradiction.

We remark that there are other examples where every maximal subfield of $D_{1} \otimes_{K} D_{2}$ is a composite. In [4] an example is constructed of a field $K$ and two quaternions $D_{1}$ and $D_{2}$ over $K$ such that every maximal subfield of $D_{1} \otimes_{K} D_{2}$ (which is a division ring) is a composite.

Our final result shows that over number fields it is never the 
case that every maximal subfield of a tensor product is a composite. We use freely the classification of rational division algebras by means of Hasse invariants [2, Chapter 9].

THEOREM 4. Let $K$ be an algebraic number field, $D_{1}$ and $D_{2}$ $K$-division rings such that $D_{1} \otimes_{K} D_{2}$ is a division ring. Then there are infinitely many maximal subfields of $D_{1} \boldsymbol{\otimes}_{K} D_{2}$ which are not composites.

Proof. Suppose that $\left[D_{1}: K\right]=n^{2},\left[D_{2}: K\right]=m^{2}$ and $m<n$. Let $\left[\mathscr{P}_{1}, \cdots, \mathscr{P}_{m}\right\}$ be the set of finite primes of $K$ for which the Hasse invariants of $D_{1} \otimes_{K} D_{2}$ are nonzero. Let $\mathscr{P}$ be a finite prime of $K, \mathscr{P} \notin\left\{\mathscr{P}_{1}, \cdots, \mathscr{P}_{m}\right\}$. Let $K_{i}$ be the completion of $K$ at $\mathscr{P}_{i}, K_{\mathscr{P}}$ the completion of $K$ at $\mathscr{P}$. Let $K_{i}\left(\alpha_{i}\right)$ have degree $m n$ over $K_{i}$ and $K_{\mathscr{P}}(\alpha)$ have degree $n$ over $K_{\mathscr{P}}$. We write $f_{i}(x)$ for the monic minimal polynomial of $\alpha_{i}$ over $K_{i}$ and $f(x)$ for the monic minimal polynomial of $\alpha$ over $K_{\mathscr{P}}$. Let $g(x)$ be monic in $K[x]$ of degree $n m$ "sufficiently close" to $f_{i}(x)$ in the $\mathscr{P}_{i}$-topology, $i=1, \cdots, m$, and "sufficiently close" to $(x-1)^{n m-n} f(x)$ in the $\mathscr{P}$-topology. If $n m$ is even, take $g(x)$ also "sufficiently close" to $\left(x^{2}+1\right)^{m n / 2}$ at all infinite primes of $K$. Here "sufficiently close" means close enough to guarantee

(1) $g(x)$ is irreducible over $K$

(2) For any root $\beta$ of $g(x)$, the field $L=K(\beta)$ has local degree $n m$ at $\mathscr{P}_{i}, i=1, \cdots, m$, and $\mathscr{P}$ splits into $n(m-1)$ primes of degree one and one prime of degree $n$ in $L$.

(3) If $n m$ is even, $L$ is totally imaginary.

This is possible by [6, Ex. 3.2, p. 116].

It follows from the theory of Hasse invariants that $L$ splits $D_{1} \otimes_{K} D_{2}$. Since $[L: K]=n m, L$ is a maximal subfield of $D_{1} \otimes_{K} D_{2}$. Suppose there were a field $E, L \supset E \supset K,[E: K]=n$. If $\pi$ is a prime of $E$ dividing $\mathscr{P}$ of degree greater than one, then $\pi$ must remain irreducible in $L$ since otherwise $L$ would have two primes of degree $>1$ dividing $\mathscr{P}$. But then if $\gamma$ is the prime of $L$ extending $\pi$, the local degree of $\gamma$ over $\mathscr{P}$ is divisible by $[L: E]=m$. Thus $m$ would divide $n$ which is not the case since $D_{1} \otimes_{K} D_{2}$ is a division ring. This shows that $\mathscr{P}$ splits completely in $E$. But then the local degree of any prime of $L$ dividing $\mathscr{P}$ is at most $[L: E]=m<n$. This proves that $E$ can not exist and so $L$ is not a composite. Since there are infinitely many choices for $\mathscr{P}$, there are infinitely many such $L$. 


\section{REFERENCES}

1. A. A. Albert, A note on cyclic algebras of order 16, Bull. Amer. Math. Soc., 37 (1931), 727-30.

2. - Structure of algebras, Amer. Math. Soc. Colloq. Publ., 24, Amer. Math. Soc., Providence, R.I., 1939.

3. - On p-adic fields and rational division algebras, Ann. Math., 41 (1940), 674-693.

4. S. Amitsur, On central division algebras, to appear Israel J. Math., 12 (1972), 408421.

5. M. Schacher, Subfields of division rings, I, J. of Algebra, 9 (1968), 451-477.

6. E. Weiss, Algebraic number theory, McGraw-Hill, New York, 1963.

Received November 11, 1971. This research was supported in part by National Science Foundation grants GP-29068 and GP-28696.

OREgon State UNIVERSity

AND

UNiversity of CALIForNia, LOS ANGeles 



\section{PACIFIC JOURNAL OF MATHEMATICS}

\section{EDITORS}

\author{
H. SAMELson \\ Stanford University \\ Stanford, California 94305 \\ C. R. HоввY \\ University of Washington \\ Seattle, Washington 98105
}

J. DugundJI

Department of Mathematics

University of Southern California

Los Angeles, California 90007

RICHARD ARENS

University of California

Los Angeles, California 90024

\section{ASSOCIATE EDITORS}
E. F. BeCKENBACH
B. H. NEUMANN
F. WOLF
K. YoshidA

\section{SUPPORTING INSTITUTIONS}

UNIVERSITY OF BRITISH COLUMBIA

CALIFORNIA INSTITUTE OF TECHNOLOGY

UNIVERSITY OF CALIFORNIA

MONTANA STATE UNIVERSITY

UNIVERSITY OF NEVADA

NEW MEXICO STATE UNIVERSITY

OREGON STATE UNIVERSITY

UNIVERSITY OF OREGON

OSAKA UNIVERSITY

\author{
UNIVERSITY OF SOUTHERN CALIFORNIA \\ STANFORD UNIVERSITY \\ UNIVERSITY OF TOKYO \\ UNIVERSITY OF UTAH \\ WASHINGTON STATE UNIVERSITY \\ UNIVERSITY OF WASHINGTON

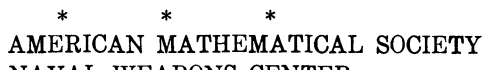 \\ NAVAL WEAPONS CENTER
}

The Supporting Institutions listed above contribute to the cost of publication of this Journal, but they are not owners or publishers and have no responsibility for its content or policies.

Mathematical papers intended for publication in the Pacific Journal of Mathematics should be in typed form or offset-reproduced, (not dittoed), double spaced with large margins. Underline Greek letters in red, German in green, and script in blue. The first paragraph or two must be capable of being used separately as a synopsis of the entire paper. The editorial "we" must not be used in the synopsis, and items of the bibliography should not be cited there unless absolutely necessary, in which case they must be identified by author and Journal, rather than by item number. Manuscripts, in duplicate if possible, may be sent to any one of the four editors. Please classify according to the scheme of Math. Rev. Index to Vol. 39. All other communications to the editors should be addressed to the managing editor, Richard Arens, University of California, Los Angeles, California, 90024.

50 reprints are provided free for each article; additional copies may be obtained at cost in multiples of 50 .

The Pacific Journal of Mathematics is issued monthly as of January 1966. Regular subscription rate: $\$ 48.00$ a year (6 Vols., 12 issues). Special rate: $\$ 24.00$ a year to individual members of supporting institutions.

Subscriptions, orders for back numbers, and changes of address should be sent to Pacific Journal of Mathematics, 103 Highland Boulevard, Berkeley, California, 94708.

PUBLISHED BY PACIFIC JOURNAL OF MATHEMATICS, A NON-PROFIT CORPORATION

Printed at Kokusai Bunken Insatsusha (International Academic Printing Co., Ltd.), 270, 3-chome Totsuka-cho, Shinjuku-ku, Tokyo 160, Japan. 


\section{Pacific Journal of Mathematics}

\section{Vol. 45, No. $2 \quad$ October, 1973}

Kenneth Paul Baclawski and Kenneth Kapp, Induced topologies for quasigroups and loops ............................................. 393

D. G. Bourgin, Fixed point and $\min -\max$ theorems $\ldots \ldots \ldots \ldots \ldots \ldots \ldots$

J. L. Brenner, Zolotarev's theorem on the Legendre symbol ............... 413

Jospeh Atkins Childress, Jr., Restricting isotopies of spheres .............. 415

John Edward Coury, Some results on lacunary Walsh series ................ 419

James B. Derr and N. P. Mukherjee, Generalized Sylow tower groups. II . . . . . . 427

Paul Frazier Duvall, Jr., Peter Fletcher and Robert Allen McCoy, Isotopy Galois

spaces .......................................... 435

Mary Rodriguez Embry, Strictly cyclic operator algebras on a Banach space ... 443

Abi (Abiadbollah) Fattahi, On generalizations of Sylow tower groups ......... 453

Burton I. Fein and Murray M. Schacher, Maximal subfields of tensor products . . 479

Ervin Fried and J. Sichler, Homomorphisms of commutative rings with unit

element .......................................... 485

Kenneth R. Goodearl, Essential products of nonsingular rings ............. 493

George Grätzer, Bjarni Jónsson and H. Lakser, The amalgamation property in

equational classes of modular lattices ...........................

507

$\mathrm{H}$. Groemer, On some mean values associated with a randomly selected simplex

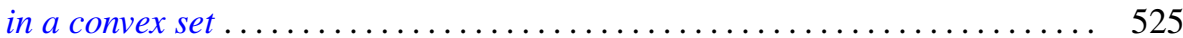

Marcel Herzog, Central 2-Sylow intersections .................... 535

Joel Saul Hillel, On the number of type-k translation-invariant groups ........ 539

Ronald Brian Kirk, A note on the Mackey topology for $\left(C^{b}(X)^{*}, C^{b}(X)\right) \ldots \ldots .543$

J. W. Lea, The peripherality of irreducible elements of lattice.............. 555

John Stewart Locker, Self-adjointness for multi-point differential operators ..... 561

Robert Patrick Martineau, Splitting of group representations ............... 571

Robert Massagli, On a new radical in a topological ring ................. 577

James Murdoch McPherson, Wild arcs in three-space. I. Families of Fox-Artin

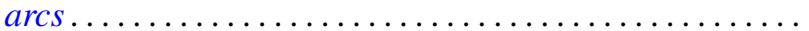

585

James Murdoch McPherson, Wild arcs in three-space. III. An invariant of

oriented local type for exceptional arcs . . . . . . . . . . . . ............ 599

Fred Richman, The constructive theory of countable abelian p-groups ........ 621

Edward Barry Saff and J. L. Walsh, On the convergence of rational functions

which interpolate in the roots of unity ..................

Harold Eugene Schlais, Non-aposyndesis and non-hereditary

decomposability..................................... 643

Mark Lawrence Teply, A class of divisible modules................... 653

Edward Joseph Tully, Jr., H-commutative semigroups in which each

homomorphism is uniquely determined by its kernel ................. 669

Garth William Warner, Jr., Zeta functions on the real general linear group ...... 681

Keith Yale, Cocyles with range $\{ \pm 1\} \ldots \ldots \ldots \ldots \ldots \ldots \ldots \ldots \ldots \ldots \ldots \ldots \ldots . \ldots \ldots$

Chi-Lin Yen, On the rest points of a nonlinear nonexpansive semigroup ........ 699 